\title{
EDUCAÇÃO BRASILEIRA: \\ $O$ futuro e o passado perspectivados pelo presente
}

\author{
José Carlos Souza Araujo ${ }^{1}$ \\ Universidade Federal de Uberlândia (UFU)
}

\begin{abstract}
Todo ser humano tem consciência do passado [...] em virtude de conviver com pessoas mais velhas. [...] O passado é, portanto, uma dimensão permanente da consciência humana, um componente inevitável das instituições, valores e outros padrões da sociedade humana. As pessoas não podem evitar a tentativa de antever o futuro mediante alguma forma de leitura do passado. Elas precisam fazer isso. [...] E é claro que as pessoas o fazem com base na suposição justificada de que, em geral, o futuro está sistematicamente vinculado ao passado, que, por sua vez, não é uma concatenação arbitrária de circunstâncias e eventos. (HOBSBAWM, 1998, p. 50).
\end{abstract}

O que agora claramente transparece é que nem há tempos futuros nem pretéritos. É impróprio afirmar que os tempos são três: pretérito, presente e futuro. Mas talvez fosse próprio dizer que os tempos são três: presente das coisas passadas, presente das presentes, presente das futuras. [...] Diga-se também que há três tempos: pretérito, presente e futuro como ordinária e abusivamente se usa. Não me importo nem me oponho nem critico tal uso, contanto que se entenda o que se diz e não se julgue que aquilo que é futuro já possui existência, ou que o passado subsiste ainda. (AGOSTINHO, 1973, p. 248).

A memória, onde cresce a história, que por sua vez a alimenta, procura salvar o passado para servir o presente e o futuro. Devemos trabalhar de forma a que a memória coletiva para a libertação e não para a servidão dos homens. (LE GOFF, 1996, p. 477).

\section{RESUMO}

O objeto deste se explicita em torno de uma reflexão que sugere aspectos fundamentais ligados à história educacional brasileira particularmente do século XX: ainda que o objeto da história seja o passado, o presente e o futuro estão implicitamente inseridos na elaboração historiográfica, e em particular na de caráter educacional. Se as diferentes interpretações que, aliás, sempre se renovam pelas diferentes tendências historiográficas, questionam os sentidos atribuídos ao passado, o presente delas participa e compartilha; no mesmo sentido, o passado elaborado historiograficamente deixa entrever também indagações sobre o futuro, posto que implicitamente vincula-se a um projeto social do ponto de vista do presente. Nessa direção, exemplifica-se a partir do papel de algumas tecnologias educativas - como o cinema, as máquinas de ensinar, os computadores em rede etc - que já foram (ou continuam a ser) objeto de esperanças, aspirações e previsões no passado (ou também no presente) histórico-educacional. Passado, presente e futuro participam das atividades do historiador, ainda que seu objeto seja o passado.

Palavras-chave: Passado; Presente: Futuro; Educação Brasileira: Tecnologia Educativa. 


\title{
BRAZILIAN EDUCATION: the future and the pass perspectived by the present
}

\begin{abstract}
The aim of this article is to clarify the fundamental aspects, related with the Brazilian Educational History, specifically the 20th Century one. Although the object of history is the past, the present and the future are implicitly inserted in the historiographical construction, particularly in the educational character. If different interpretations, which always renew through different historiographical tendencies, inquire the meanings assigned to the past, the present participates and shares it as well; by the same token, the historiographically,elaborated past, leaves us questions for the future, since it is implicitly related with the present social point of view. In this direction, it exemplifies the role of educational technologies - cinema, teaching machines, computer networks, which were or are the object of hopes, aspirations and foresights in the past (as well as in the present) historical-educational situation. Past, present and future take part in the activities of the history researcher, even if the object of analysis is still the past.
\end{abstract}

Keywords: Past; Present; Future; Brazilian Education; Educative Technology.

O termo perspectiva, expresso no subtítulo deste, impõe algumas considerações iniciais. Porque em seu primeiro significado como sinônimo implica uma técnica de representação em três dimensões, por exemplo, presente na pintura: imaginemos uma casa rodeada de rosas ao fundo, mas, em primeiro plano, com palmeiras à frente. Tem-se assim uma pintura em perspectiva, cuja representação implica em diminuição das figuras que ocupam o segundo plano.

Somente por extensão de sentido, perspectiva significa, em termos de sinônimo, vista ao longe ou até onde os olhos alcançam. Nessa direção, e utilizando-se da imaginação, o termo perspectiva confunde-se com aparência, com expectativa, com sentimento de esperança.

E é com essa extensão de sentido, o objeto deste: como ver ao longe a educação no século XXI que se inicia, e completou apenas onze anos? Diríamos que o século XXI é uma criança. É como falar de uma criança que irá ser adolescente, jovem, depois adulto, que entrará em processo de envelhecimento e, depois, atingirá a velhice, próximo do ano 2100.

Como falar de educação até onde os olhos alcançam? Falaremos de aparências, de indícios, de previsões, de ilusões, de conjecturas, de esperanças ou simplesmente de projeções estatísticas, de caráter educacional, com base nos últimos dez anos ou vinte anos? Ou, em termos de educação, é possível somente considerar as práticas educativas, as quais envolvem práticas pedagógicas que, por sua vez, envolvem práticas didáticas? Todavia, como falar do futuro das práticas?

Ou é possível apenas falar de teorias pedagógicas que expressem reflexões mais totalizantes ou apenas parciais, e que devam servir às práticas? O que vem por primeiro: práticas ou teorias? Quando se fala em educação, significa que esteja se falando da escola? E quando se trata de escola, está se tratando de educação, uma vez que a escola veio se constituindo hegemonicamente, no decorrer do século XX, como uma forma superior e sistemática de socialização? Tal modelo de educação e de socialização continuará sendo hegemônico, ou as novas tecnologias educativas serão capazes de estabelecer a socialização global pelos computadores em rede sustentados pela internet? Se sim, a 
educação à distância substituirá a educação presencial? É ela uma forma democrática e de qualidade?

Apropriadamente, a $2^{\mathrm{a}}$. LDB, de 20 de dezembro de 1996, reza em seu artigo $1^{\circ}$ : “A educação abrange os processos formativos que se desenvolvem na vida familiar, na convivência humana, no trabalho, nas instituições de ensino e pesquisa, nos movimentos sociais e organizações da sociedade civil e nas manifestações culturais". E que o objeto da referida LDB é a educação escolar, a qual deverá vincular-se ao mundo do trabalho e à prática social (artigos $2^{\circ}$ e $3^{\circ}$ ).

Uma certeza é afirmável: ao se abordar a respeito de perspectivas para a educação no século XXI, o futuro está à nossa frente. Os 10 anos de idade já completados do século XXI faz parte do passado. Eles já se foram, e não voltam!

A propósito ainda de uma definição de termos: perspectiva e prospectiva significam a mesma coisa. Prospectiva implica em uma ação de olhar para frente, mas é de um olhar à distância não sobre o que se tem na memória, mas a de um olhar à distância sobre o que ainda não existe, o futuro. Prospectar significa então olhar de longe e, se se exagerar, pode significar até adivinhar o futuro, sinonimicamente falando.

Ter em perspectiva a educação é esperar que ela seja futuramente, como se desenha presentemente aos nossos olhos. Porém, ela será aquilo que se espera que seja? Com uma escola integral? Num país sem analfabetismos absoluto e funcional, ou apenas com um percentual, alto ou baixo, de analfabetismo funcional? Com uma política educacional articulada para os níveis da Educação Básica (Educação Infantil, Fundamental e Média) e Superior? Com uma formação inicial e continuada condizente com os problemas, as necessidades e as aspirações de hoje?

Daqui a pouco menos de 90 anos, o século XXI se completará; por isso abordar a respeito dele, é ter como provável o que se considera a partir de hoje. De certa forma, discutir e elaborar perspectivas para o século XXI que ainda virá, é considerar a aparência que poderá ter, mas da maneira como se apresenta aos nossos olhos de hoje, com os problemas e as necessidades de hoje.

Santo Agostinho (354-430), em sua obra, Confissões, escrita em torno do ano 400, e ele estaria então com 46 anos -, no Livro XI (décimo primeiro), intitulado $O$ homem e $o$ tempo, afirma em sustentação a essa posição:

[...] dizemos tempo longo ou breve, e isto, só o podemos afirmar do futuro ou do passado. Chamamos "longo" ao tempo passado, se é anterior ao presente, por exemplo, cem anos. Do mesmo modo dizemos que o tempo futuro é "longo", se é posterior ao presente também cem anos. Chamamos "breve" ao passado, se dizemos, por exemplo, "há dez"; e ao futuro, se dizemos "daqui a dez dias". Mas como pode ser breve ou longo o que não existe? Com efeito, o passado já não existe e o futuro ainda não existe. (AGOSTINHO, 1973, p. 244).

Evidentemente, o futuro breve (ou o futuro imediato) - levando-se em conta também a história de vida pessoal, bem como aquilo que está guardado na memória, vinculado à experiência que a vida traz -, é mais previsível, pelo menos em linhas gerais. Porém, com relação ao futuro longo, corre-se o risco de construir projeções descabidas, ou mesmo de fazer idealizações, ou seja, de imaginar de maneira ideal ou até fantasiada.

A respeito de tais projeções ou idealizações sobre o futuro longo e mesmo sobre o futuro breve, vou trazer quatro exemplos da área da educação. Para isso, vou a um passado mais ou menos distante, mas permanecerei no âmbito do século XX. Ressalto desde já que 
tais exemplificações são sobre o presente de então, isto é, quando ocorreram; e que nós, vivendo o tempo presente de hoje, avaliemos.

Primeiro exemplo em torno de 40 anos atrás: a obra de Skinner, intitulada Tecnologia do Ensino - vinda a público nos Estados Unidos em 1968, mas no Brasil fora publicada em 1972 -, é exemplar quanto a esse aspecto. Concebendo que "a educação é, talvez, o mais importante ramo da tecnologia científica" (SKINNER, 1972, p. 18), afirma, em referência às máquinas de ensinar, que "há trabalho mais importante a ser feito, no qual as relações da professora com o aluno não podem ser duplicadas por um aparelho mecânico. Os recursos instrumentais só virão melhorar estas relações insubstituíveis" (SKINNER, 1972, p. 25).

Assim sendo, sua posição é de que as máquinas de ensinar não substituirão os professores, mas cabem a estes, segundo ele, com o auxílio das referidas máquinas, "ensinar mais alunos do que até então [...] em menos horas e com menos fainas pesadas. Em troco desta sua maior produtividade, pode pedir que a sociedade melhore sua condição econômica"(SKINNER, 1972, p. 54). Ou seja: concretamente, o professor poderia ter melhor salário.

Skinner também reconhece que a tecnologia do ensino poderia ser usada imprudentemente, bloqueando a iniciativa, a criatividade, e mesmo tornando "[...] todos os homens parecidos uns com os outros" (SKINNER, 1972, p. 87). Porém, em termos de positividade, afirma que a mesma tecnologia do ensino "[...] poderá maximizar a dotação genética de cada estudante; poderá torná-lo tão hábil, competente e informado quanto possível; poderá criar a maior diversidade de interesse; poderá levá-lo às maiores contribuições possíveis para o desenvolvimento e a sobrevivência de sua cultura [...]" (SKINNER, 1972, p. 87). Conclusivamente, afirma a centralidade da tecnologia do ensino, predizendo que "[...] o governo do futuro provavelmente funcionará principalmente através de técnicas educacionais" (SKINNER, 1972, p. 248). Desde já, qualquer semelhança com expectativas e representações contemporâneas a respeito das tecnologias de informação e de comunicação (TICs) é mera coincidência.

Parafraseando a afirmação de Marx de que a técnica e os produtos tecnológicos apresentam-se como uma vitória do homem sobre a força da natureza (MARX, 1982, p. 506), pode-se ressaltar que as tecnologias educativas constituem uma vitória do homem sobre os processos mecânicos de ensino e sobre os processos centralmente verbais presentes em outros momentos da história da escola, fundados, por exemplo, na recitação, na memorização, na narração, na leitura, na repetição, no ditado etc.

Nesse sentido, as técnicas de ensino e as tecnologias educativas se constituem em instrumentos de intervenção para construir o futuro da humanidade. A técnica e a tecnologia são mediações a intervir sobre os sujeitos humanos - alunos -, através de sujeitos humanos - os professores - que visam a construção do próprio ser humano. Aqui está o fulcro da educação, a intersubjetividade.

Passemos agora ao segundo exemplo, e de um passado mais distante, com 90 anos, mas que foi presente naquele momento, porém afirmava a futuridade: em uma reportagem de 1921, de um jornal de Uberabinha, MG (atual Uberlândia, desde 1929), considerava-se esperançosamente o papel do cinema numa escola normal de Belo Horizonte:

Devemos á iniciativa do exmo sr. Dr. Affonso Penna Junior e de haver installado, na Escola Normal desta cidade, um cinema destinado a auxiliar o ensino, principalmente. A introdução do cinema no ensino, em Bello Horizonte, é mais um poderoso attestado de quanto S. Ex.a. se interessa pela instrucção em nosso Estado, prestigiando-a, volvendo as 
vistas com affectuoso carinho para os pequenos, ampliando, amenizando a estrada que os conduzirá, suavemente, às gloriosas esperanças do futuro. (ALVIM, p.1, 02/011/1921).

Essa matéria jornalística caracteriza-se pelas seguintes dimensões: o cinema como auxiliar do ensino, tal auxílio enquanto devotado às crianças, e a formação, pela tecnologia educativa do cinematógrafo, da futura normalista. Mas a afirmação de que tal auxílio amplia e ameniza a estrada em vista das esperanças do futuro, situa o papel educativo de uma velha tecnologia no campo educativo, depois retomada na escola pelo videocassete, depois pelo aparelho de DVD, e agora através do Blu-ray Disc, já chamado por BD, em torno do qual também já existem perspectivas de superação.

Terceiro exemplo, a propósito de mais de 30 anos atrás: a posição de Lyotard, na obra O Pós-Moderno, vinda ao público em 1979 - e fundadora da discussão sobre a pósmodernidade no campo das Ciências Humanas - apresenta em seu capítulo 12, $O$ ensino $e$ sua legitimação pelo desempenho, uma reflexão sobre o futuro da universidade pautado na perspectiva da formação de competências - esta uma categoria central nas discussões a respeito da formação de professores -, do desempenho pragmático de papéis, da melhoria das performances do sistema fundada na reciclagem permanente. Dizia ele:

Fora das universidades, departamentos ou instituições de vocação profissional, o saber não é e não será mais transmitido em bloco e de uma vez por todas a jovens antes de sua entrada na vida ativa; ele é e será transmitido à la carte a adultos já ativos ou esperando sê-lo [...]. (LYOTARD, 1986, p. 90).

Tal previsão, segundo ele ao modo à la carte, procurará melhorar a sua competência e a sua promoção, mas visará à aquisição de informações em vista da vida profissional, entre outros aspectos.

Continua ele: através do ensino superior, e tratando-se de profissionalização, “[...] o essencial do transmissível é constituído por um estoque organizado de conhecimentos" (LYOTARD, 1986, p. 91).

[...] Na medida em que os conhecimentos são traduzíveis em linguagem informática, e enquanto o professor tradicional é assimilável a uma memória, a didática pode ser confiada a máquinas articulando as memórias clássicas (bibliotecas, etc.) bem como os bancos de dados a terminais inteligentes colocados à disposição dos estudantes. (LYOTARD, 1986, p. 92).

Sob essa perspectiva, faz a defesa de que cabe ensinar “[...] não os conteúdos, mas o uso dos terminais, isto é, de novas linguagens [...] (LYOTARD, 1986, p. 92), mas também de uma formação elementar em informática ${ }^{2}$ e em telemática ${ }^{3}$. Para ele, "[...] a enciclopédia de amanhã são os bancos de dados. Eles excedem a capacidade de cada usuário. Eles são a 'natureza' para o homem pós-moderno" (LYOTARD, 1986, p. 93). Entretanto, para o mesmo, isso implica na capacidade de manter tais bancos de dados atualizados.

Conclusivamente ao referido capítulo de Lyotard, aponta ele que as instituições do saber em todo o mundo terão como solução assumir a dissociação de dois aspectos da didática: a) o da reprodução 'simples' e b) o da reprodução 'ampliada'. Para atender ao primeiro, a reprodução simples, os canais de transmissão " [...] poderão ser simplificados e generalizados; os segundos [aqueles atingidos pela reprodução ampliada] têm direito aos 
pequenos grupos que funcionam num igualitarismo aristocrático" (LYOTARD, 1986, p. 95). Em outras palavras, para muitos uma reprodução simples; e para poucos, uma reprodução aristocratizada - ou elitista, se quiserem - fundada, por exemplo, em grupos de pesquisas e através de orientações individualizadas.

Em seguida, conclui o mencionado capítulo 12 com a seguinte afirmação:

[...] o que parece certo, é que nos dois casos - [reprodução de conteúdos para muitos, e reprodução aristocratizada dos conteúdos para poucos] - a deslegitimação e a prevalência do critério do desempenho soam como a hora final do Professor: ele não é mais competente que as redes de memórias para transmitir o saber estabelecido, e ele não é mais competente que as equipes interdisciplinares para imaginar novos lances ou novos jogos. (LYOTARD, 1986, p. 95-96).

Tais posições, a de Skinner e a de Lyotard, estão referidas à sobrelevação das tecnologias no processo de ensino e de aprendizagem. São inegáveis as contribuições das mesmas a mediar o processo educativo, mas elas trazem à recordação o alerta sempre presente de uma obra clássica, Apocalípticos e Integrados de Umberto Eco, referente à cultura de massa.

Diante das tecnologias educativas, não se trata de assumir o consenso de que trariam soluções ao árduo convívio entre o ensino e a aprendizagem - uma posição integrada -, nem de promover o dissenso, procurando apontar a decadência do ensinoaprendizagem - uma posição apocalíptica. As posições em apreço - a apocalíptica e a integrada manifestam, respectivamente, de um lado, uma tecnofobia - medo diante da técnica - e, de outro, uma tecnofilia - amor à técnica.

A posição integrada assumiria que as tecnologias educativas são os carros-chefes para a redenção do ensino e da aprendizagem; em tal posição, confessa-se um otimismo tecnológico-educativo em vista da dimensão pedagógica e didática.

Por outro lado, a posição apocalíptica assumiria que tais deslocamentos, quanto ao papel das tecnologias educativas, seriam catastróficos e alienantes, nada trazendo para o ensino e a aprendizagem, a não ser o desvio provocado pelas mesmas tecnologias.

As predições de Skinner e de Lyotard comentadas anteriormente traduzem aspirações e anseios que realizam a defesa da integração à tecnologia pelo campo educativo. A sinalização de que chegou a 'hora final do Professor', ou de que ele será substituído pelas máquinas de ensinar ou pelos bancos de dados, bem como pelos computadores em rede - e, por esta razão, sua produtividade seria maior -, parecem situar a educação para além das relações que se constróem entre os sujeitos, professores e alunos.

Ainda que distingamos a educação entre formal e informal, ou entre doméstica e pública, ela é um fenômeno que envolve sujeitos - realizam uma intersubjetividade -, que busca realizar a sociabilidade numa dada cultura assentada na historicidade. No âmbito de tais aspectos fenomênicos que se explicitam ao próprio existir, a educação é ainda necessariamente socializadora, intergeracional e projetiva, constituindo-se como uma mediação. E as tecnologias novas ou antigas, bem como as técnicas e os métodos - de origem tradicional, intuitiva, escolanovista ou de orientação tecnicista - constituem-se como interposições a interceder a favor do projeto de construção do próprio homem. Se elas não servem a isso, sua razão de ser não é humana.

A propósito das novas tecnologias educativas - denominadas por tecnologias de informação e comunicação (TICs) - manifesto uma preocupação: elas se destinam à informação e à comunicação, e certamente em principio são mediações para o conhecimento, para a construção do conhecimento. Mas não constituem por si mesmas em 
conhecimento. Digamos que sejam mediações para se construir e constituir o conhecimento.

Uma exemplificação: o livro de papel é uma tecnologia educativa que nasceu há mais de quinhentos anos, e se configura como uma ferramenta para o conhecimento, mas não é o conhecimento; o CD foi inventado em 1979, o DVD o foi em 1995, mas são mediações tecnológicas para a elaboração do conhecimento. A internet tem sua origem nos anos de 1960, mas sua inserção no Brasil se realiza concretamente nos primeiros anos de 1990.

AS TICs têm repercussões diversas no campo educativo, inclusive por associações entre si: bancos de dados, sites, teleconferências, chats, computadores em rede (telemática), correio eletrônico (e-mails), web (www - World Wide Web - ambiente multimídia da Internet que reúne texto, imagem, som, vídeo e movimento), a telefonia, a televisão e o cinema pela Internet, a educação à distância.

Constituem-se todos potencialmente como veículos de informação e comunicação, e certamente a vida cultural, a educação, a escola, o ensino, a aprendizagem, a didática já compartilham e compartilharão de tais TICs, mas é imprevisível o seu papel na educação, bem como suas formas de acesso e utilização nas aulas e nas diferentes salas de aula. Mas não significa dizer que não hajam tendências. Mas isso não significa que não tenhamos avaliações a favor e contrárias às mesmas, pelo menos para compreender suas possibilidades e seus limites.

Mas, não sejamos integrados, pois o conhecimento é uma construção, porém ele precisa ser construído. Ainda que as tecnologias educativas - o cinema e o projetor de slides nos anos de 1920, o retroprojetor dos anos de 1940, a fita cassete lançada nos anos de 1960, o videocassete nos anos de 1970, o projetor multimídia em 1990, o datashow ${ }^{4}$-, representem uma vitória sobre os processos mecânicos e repetitivos, o conhecimento humano se estrutura pelo estudo e pela pesquisa.

E são aí substituíveis as novas tecnologias educativas, uma vez que as tecnologias precisam da razão, da memória, da intuição e da imaginação. Tais faculdades são denominadas por cognitivas, e são elas que possibilitam a cognição ou o conhecimento.

Ainda que os bancos de dados constituam a natureza para o homem pós-moderno, como sustenta Lyotard, diria que o homem antes de ser moderno, ou mesmo sendo pósmoderno, nada teria feito sem as faculdades 'espirituais', ou 'da alma' ou 'da mente', ou chamadas também por 'poder cognitivo' ou mesmo por 'poder conceptual' que possibilitam o poder de conhecer ou o poder de conceber - ou outras denominações que possam melhor esclarecer o que sejam tais faculdades.

Evidentemente, tais faculdades precisam ser desenvolvidas, elas não estão simplesmente dadas ao nascer, ou aparecem depois de alguns ou depois de muitos anos após o nascimento. O estudo e a pesquisa, com essas tecnologias ou com aquelas tecnologias, configuram-se como caminho para a construção do conhecimento.

Certamente, a circulação de informação e a curiosa busca pela mesma por parte da criança, do adolescente e de todos nós passam pela experiência de existir e pela aventura da busca pelo conhecimento. A informação e a comunicação constituem-se operacionalmente das evidências empíricas buscadas e conseguidas, com as quais convivemos diariamente.

Porém, sem o exercício da observação, da análise, da explicação, do entendimento, da compreensão, de nada adiantariam a informação e a comunicação. Elas constituem a matéria prima da cognição ou do conhecimento, mas não são a cognição, ainda que possam ser alavancas para a mesma. Evidentemente, a cognição é construída como sustenta o 
construtivismo, porém, sem o envolvimento do construtor ou do construinte nada se faz possível.

Já está superada a perspectiva que situava a tecnologia educativa como o estudo dos meios como promotores de eficiência do ensino e geradores, ipso facto, de aprendizagem. Essa concepção é dos anos de 1950 e de 1960. A crítica a essa orientação tecnicista fez-se adequadamente, bem como propiciou outro posicionamento desde os anos de 1970: a concepção que define a tecnologia educativa por seu estudo do ensino como processo tecnológico.

A propósito: está na raiz do termo tecnologia e de outros correlatos o vocábulo $\tau \dot{\varepsilon} \chi v \eta:$ "[...] os gregos usavam o [referido] termo (frequentemente traduzido por ars, 'arte', e que é a raiz etimológica de 'técnica'), para designar uma habilidade mediante a qual se faz algo - geralmente se transforma uma realidade natural em uma realidade 'artificial'. [...] Em geral, téchne é toda série de regras por meio das quais se consegue algo" (MORA, 1982, verbete: técnica).

Até aqui falamos do futuro, mas a partir do passado que era então presente: uma matéria jornalística de 1921, uma obra de Skinner de 1968 e a obra de Lyotard sobre a condição pós-moderna, lançada em 1979. Eram todas as três vinculadas ao presente quando se deram a público, mas não deixaram de fazer previsões, de abrir perspectivas para a educação de então, através de tecnologias educativas: o cinema, as máquinas de ensinar e os bancos de dados associados aos computadores em rede. Através de tais tecnologias, procurava-se ver ao longe, e até onde os olhos alcançavam. Traduziam expectativas, faziam previsões, confessavam esperanças em torno do cinema, das máquinas de ensinar e dos bancos de dados.

A essa altura, parece que vale a pena voltar à reflexão de Agostinho sobre o tempo, uma vez que pode trazer luzes para compreender o tempo futuro:

Se existem coisas futuras e passadas, quero saber onde elas estão. Se ainda o não posso compreender, sei todavia que em qualquer parte onde estiverem, aí não são futuras nem pretéritas, mas presentes. Pois, se também aí são futuras, ainda lá não estão; e, se nesse lugar são pretéritas, já lá não estão. Por conseguinte, em qualquer parte onde estiverem, quaisquer que elas sejam não podem existir senão no presente. (AGOSTINHO, 1973, p. 246).

Diante de tais observações, falar de perspectivas educacionais é procurar avistar ao longe a partir do presente - mas, eu acrescentaria, também a partir da memória e da experiência que se tem do passado, pelo menos das gerações vivas que se lembram dele. Se o futuro e o passado não existem, pelo menos o passado conta com a investigação histórica, uma forma de acedê-lo. Nessa direção, a história poderia cumpriria o papel de dar existência a uma identidade cultural para aqueles que vivem o presente. Não se trata aqui de afirmar que o passado deva ser objeto de aprendizagem para a vida da humanidade no presente. A história não é mestra da vida, como já se afirmou e se acreditou.

Não parece questionável que a história contribua para a constituição da identidade cultural dos tempos contemporâneos - e especial somente deles; a investigação histórica, e em particular a pesquisa histórico-educacional, põe em circulação e em questão os bastidores de nossa identidade cultural atualmente reinante. Sendo fiel a Agostinho, diríamos que o passado educacional somente pode existir no presente como forma de investigação, e é com ele que indagamos sobre o passado.

Estejamos ou não na pós-modernidade ou a caminho da pós-modernidade, os chamados metarrelatos ou metanarrativas ${ }^{5}$ da modernidade estão a costurar o presente. 
Porém, o presente é um fluxo, como se fosse correnteza de um rio. Porque o presente não é permanente, ele atualiza constantemente o passado, construindo inicialmente o passado mais próximo. Por outro lado, aquilo que era futuro mais imediato, torna-se presente. $\mathrm{Ou}$ dito de outra forma: o presente também atualiza constantemente o futuro, inicialmente o imediato. Ou se se quiser a propósito: em relação ao movimento da história, cabe referir-se a Heráclito: 'não se pode entrar duas vezes no mesmo rio'.

E a essa frase associado, concordemos que educar implica o futuro. A criança, o adolescente - etimologicamente, aquele que está em crescimento -, o jovem e o adulto particípio passado de adolescere, o que já cresceu -, vivem em vista do futuro; seus projetos não são imediatos, ainda que a cultura contemporânea seja ansiosa pelo imediatismo, pela fluidez, pela novidade e pela busca do prazer imediato.

Já exemplificamos algumas perspectivas para a educação no século XX, no seu início ou ao seu final, através do cinematógrafo em 1921, através das máquinas de ensinar dos anos de 1950 e de 1960, bem como dos bancos de dados e dos computadores em rede desde o final dos anos de 1970.

Somente mais um exemplo, o quarto, a respeito das tecnologias educativas eletrônicas nos anos de 1960, conforme avaliação de um conhecido escritor da área da Didática, Luiz Alves de Mattos. Afirmava ele numa obra intitulada $O$ quadro-negro e sua utilização no ensino, e que fora revista e ampliada para a segunda edição em 1968, que a lousa virtual imobilizaria o professor: "o quadro-eletrônico, dispendioso e de difícil montagem e conservação, servirá admiravelmente para professores idosos ou paralíticos, bem como aos comodistas e cansados, que preferem dar suas aulas confortavelmente sentados na cátedra" (MATTOS, 1968, p. 108). Destaque-se que tal observação não se encontra na $1^{\mathrm{a}}$. edição de 1954 . Mas, serve esta citação como um alerta à tecnofobia.

Se, de um lado, as antigas e as novas tecnologias não garantem a aprendizagem eficientemente como se acreditava e se aspirava nos anos de 1950 e de 1960 - observe-se que tal perspectiva ainda é latente entre muitos professores. Por outro lado, é inconteste a sua presença nas salas de aula - ainda que as novas tecnologias não sejam hegemônicas em termos de utilização -, bem como os seus benefícios do ponto de vista da estruturação e de viabilização do ensino. Tal dimensão não pode ser negada, sob pena de fundar-se uma tecnofobia - como há pouco revelou Luiz Alves de Mattos pela sua obra em 1968 - que pretendesse negligenciar todo o exercício concreto de superação do verbalismo, da repetição, do ditado, da transferência do velho quadro-negro para o caderno etc.

E as perspectivas para a educação no século XXI? Trata-se de delinear considerações sobre um futuro mais imediato, ou sobre um futuro mais longo? Falar-se de um futuro mais breve, como considerou Agostinho, pode-se ter mais certeza de que ele seja semelhante ao que vivemos no presente.

Comecemos pelo analfabetismo do tempo presente: em outubro de 2009, pesquisas do IPEA (Instituto de Pesquisa Econômica Aplicada), vinculado ao Ministério do Planejamento, apontaram, conforme uma amostra de 2008, que 14 milhões de brasileiros acima de 15 anos são analfabetos. E somando-se ao analfabetismo funcional, ultrapassaria 30 milhões.

Em 1890, o analfabetismo, qualificado como monstro nas várias modalidades de publicações (livros, revistas, jornais) também nas décadas iniciais do século XX, perfazia $85 \%$ da população. Em 1950, 51\% da população brasileira se constituía como analfabeta. Em 2008, estaria com $10 \%$ da população com mais de 15 anos. Atualmente, entre os estados, o líder é a Bahia, com 1,8 milhão, seguido por São Paulo, com 1,5 milhão. Minas Gerais vem em terceiro lugar no país, com 1,3 milhão. 
Se entre 1890 e 2008, passamos de $85 \%$ para $10 \%$, qual é a perspectiva que se esboça para o futuro? Segundo o IPEA, somente em 2028 o analfabetismo estaria eliminado. A propósito, e efetivamente, não são nada otimistas as avaliações sobre a aprendizagem no âmbito da Educação Fundamental, o que lança névoas sobre a superação do analfabetismo, pelo menos do funcional.

E o futuro no Brasil, como se desenharia em vista da ampliação da pós-graduação? Em suas mais diferentes áreas, ela conta hoje com 30.000 dissertações e 10.000 teses ao ano. Pode se esperar por um Brasil diferente em termos da pesquisa que se faz, e do ensino que se qualifica? Pode-se afirmar que a pós-graduação se expandiu, ampliou-se e vem disseminando-se para além das capitais estaduais. A pós-graduação envolve, no entanto, hoje menos que $1 \%$ da população estudantil.

A escolarização em termos da Educação Fundamental encontra-se hoje generalizada. Entretanto, o ensino médio conta com apenas $36 \%$ daqueles que concluem a Educação Fundamental.

Quando em 1997 o Plano Nacional de Educação foi posto em discussão, e que foi votado e aprovado em 2001, a meta para 2010 era de que a Educação Superior cobrisse $30 \%$ da população jovem entre 18 e 24 anos, a idade ideal para cursá-la. Entretanto, os dados divulgados no primeiro semestre de 2010 explicitam que se atingiu somente 13,7\%. O que era presente em 1997, tornou-se futuro desde então aos nossos dias. Todavia, o que era futuro, está se mantendo no atual presente, ou seja, o passado permanece. Ressalte-se como é difícil refugiar-se ou isentar-se da história. Não é sem razão que se afirme a filosofia e a história como possuidoras de uma identidade comum.

E o que nos reserva o futuro? Do ponto de vista de um futuro breve, nada indica que tal nível percentual se altere significativamente. Acrescente-se que a expansão e a interiorização da Educação Superior são muito importantes em termos da democratização do acesso à mesma, particularmente desde os anos de 1990. Nesse ano, as matriculas somavam 1.540.000; em 1998, 2.125.000; em 2004, 4.163.000, cabendo ao setor privado quase 03 milhões das mesmas $(72 \%)$.

A essa altura, as pesquisas avaliativas sobre o Plano de Nacional de Educação, que vigiu até 2010, vão se multiplicar, também em vista do próximo Plano Nacional de Educação, que vigeria de 2011 a 2020. A propósito, realizou-se, entre 28 de março e $1^{\circ}$ de abril de 2010, a Conferência Nacional de Educação, peça importante para a discussão do próximo Plano Nacional de Educação.

E a respeito dos professores do Brasil? Acaba de ser publicada pela UNESCO uma pesquisa a respeito intitulada Professores do Brasil: impasses e desafios, agora em 17 de outubro de 2009, coordenada por Bernadete Gatti e Elba Siqueira de Sá Barretto.

O livro se organiza em torno dos marcos legislativos dos cursos de formação de professores, seja das licenciaturas presenciais e à distância, seja dos currículos que estruturam tal formação inicial, bem como se ocupa da formação continuada, da carreira e dos salários de docentes da Educação Básica. Aponta, em suas considerações conclusivas, para a necessidade de articulação entre as diferentes instâncias que formam professores, da necessidade de um poder central coordenador tendo em vista estruturar os rumos da educação nacional, da necessidade de estruturas formativas de docentes para a educação básica e dos currículos respectivos.

Em suas considerações finais, assevera que a formação do professor precisa de instituições com esse objetivo, uma vez que ela se faz a partir das ciências e de seus diversos campos disciplinares, configurando-se como um adendo das áreas científicas. $\mathrm{O}$ professor deveria ser formado em vista da função própria inerente à escolarização, e 
afinada com a educação básica. Nesse sentido, ela deveria partir do campo da prática, mas associada aos fundamentos metodológicos e às formas de trabalhar em sala de aula.

Ainda em suas conclusões, reclama que os conhecimentos da área disciplinar preponderam sobre os conhecimentos pedagógicos, o que secundariza e fragiliza a formação do professor. Aponta que se faz necessária maior clareza quanto ao perfil profissional de professor. E que a formação do professor da Educação Infantil precisa de fato existir. As licenciaturas no âmbito da Educação Superior são secundarizadas, seja quanto ao ensino, seja quanto à pesquisa. A formação de professores pela $\mathrm{EAD}$, dado o seu caráter individualizado, oferecerá problemas, conforme se pode situar também nas considerações finais:

Há [...] numerosos indícios de que a multiplicação de consórcios e pólos para a oferta de cursos de licenciatura à distância estaria ocorrendo sem que um projeto político-pedagógico de formação docente mais adensado no âmbito de sua articulação nacional e local tenha sido desenvolvido e compartilhado e sem que as estruturas operacionais básicas estejam funcionando adequadamente. (GATTI; BARRETTO, 2009, p. 259)

Analisa ainda particularmente o regime de tutoria no âmbito da EAD, afirmando a precarização de suas atividades:

O tutor aparece como um dos elementos mais frágeis de um processo de transformação e esvaziamento do trabalho docente, em que pese a aposta centrada nos materiais ditos 'autossuficientes' e nas tecnologias empregadas para a sua produção e disseminação. As formas de contrato e pagamento dos tutores, previstas nos consórcios, não são compatíveis com a montagem de um sistema regular de educação, que requer financiamento permanente para assegurar a estabilidade de seus quadros. A condição que está sendo difundida para a sua contratação torna o vínculo do tutor com o programa extremamente vulnerável e não permite investir sistematicamente no seu aperfeiçoamento em serviço. (GATTI; BARRETTO, 2009, p. 260)

E como ficariam os estágios sob esse novo formato? Teme-se que a formação de professores através dessa modalidade “[...] poderá tornar mais frágeis os processos de formação docente e desestabilizar experiências de formação presenciais que têm mostrado sucesso" (GATTI; BARRETTO, 2009, p. 260).

Afinal, as temáticas poderiam ser multiplicadas. As perspectivas que se abrem envolvem-nos desde já. Diria que a construção do futuro se faz no presente, além de colocar-se como interrogante sobre o futuro, como se observou pela exposição. E a gestação do futuro se faz desde agora. As perspectivas impõem-nos tarefas, mas também esperanças e anseios para que ele exista diferentemente do presente.

Retomo Agostinho novamente:

Quando empreendermos e começarmos a realizar o que premeditamos, então essa ação existirá, porque já não é futura, mas presente. [...] Ora, o que já existe não é futuro, mas presente. Por conseguinte, quando se diz que se vêem os acontecimentos futuros, mas não se vêem os próprios acontecimentos ainda inexistentes - isto é, os fatos futuros -, mas sim as suas causas, ou talvez os seus prognósticos já dotados de existência. Portanto, com relação aos que os vêem, esses acontecimentos não são futuros, mas sim presentes. (AGOSTINHO, 1973, p. 247). 
A educação ou a escola pública, universal, gratuita, obrigatória e laica é um fenômeno capitalista, de origem liberal, seja em suas manifestações concretas, seja em termos de elaboração de seu ideário e de sua organização que o presente herdou. Por ela, pode nascer outra sociedade?

Parece ser inerente ao movimento histórico a afirmação e a negação: é pública, mas não é tão pública quanto se aspira, ainda que ao nível da Educação Fundamental os escores sejam importantes.

É universal, mas não é universal, uma vez que tal orientação somente depois do século XX brasileiro chegou a tanto, porém ao nível da Educação Fundamental.

É gratuita, mas não é gratuita, ainda que o acesso à Educação Fundamental esteja próximo de tal ideário.

É laica, mas não é laica, uma vez que o conflito em torno da inserção religiosa na escola tem raízes culturais que desafiam a própria militância em torno da laicidade, ou mesmo a compreensão de sua significação no próprio campo religioso.

É obrigatória, porém depois de mais de 120 anos de República, os analfabetismos absoluto e funcional ainda se situam em percentuais que contrariam a mesma obrigatoriedade.

Impasses, empecilhos, desafios, dificuldades, riscos são um vocabulário que expressa, de um lado, parte das perspectivas. Por outro, expectativas, esperanças, promessas, anseios, prospectivas, previsões, ideais, aspirações traduzem a outra face das perspectivas. Da consciência em torno do possível à consciência real em torno dos obstáculos nascem os projetos do presente histórico em vista do futuro.

Assim sendo, o futuro pode ser compreendido pelo presente. A propósito, concluo com outro trecho de Agostinho:

Vejo a aurora e prognostico que o sol vai nascer. O que vejo é presente, o que anuncio é futuro. Não é o sol que é futuro, porque esse já existe, mas sim o seu nascimento, que ainda se não realizou. [...] as coisas futuras ainda não existem; e se ainda não existem, não existem presentemente. De modo algum podem ser vistas, se não existem. Mas podem ser prognosticadas pelas coisas presentes que já existem e se deixam observar. (AGOSTINHO, 1973, p. 247).

\section{Referências}

ALVIM, Juliana. O cinema na escola. A Tribuna, Semanario Independente. Uberabinha, MG, ano II, ${ }^{\circ}$ 69, p.1, 02/011/1921.

AGOSTINHO. Confissões. São Paulo: Editora Abril, 1973.

ECO, Humberto. Apocalípticos e integrados. São Paulo, Editora Perspectiva, 1976.

GATTI, Bernadete (coord.) e BARRETTO, Elba Siqueira de Sá. Os professores no

Brasil: impasses e desafios. Brasília: UNESCO, 2009.

HOBSBAWM, Eric. Sobre História. 7ª reimpressão. São Paulo: Companhias das Letras, 2005.

LE GOFF, Jacques. História e memória. $3^{\mathrm{a}}$. Edição. Campinas, SP: Editora da Unicamp, 1994. 
LEI DE DIRETRIZES E BASES DA EDUCAÇÃO NACIONAL: nova LDB. Lei ${ }^{\circ}$ 9.394, de 20 de dezembro de 1996. Rio de Janeiro: Qualitymark Ed., 1997.

LYOTARD, Jean-François. O pós-moderno. Rio de Janeiro, José Olympio Editora, 1986.

MARX, Karl. O capital. $7^{\text {a }}$ edição. Rio de Janeiro, DIFEL, 1982, volume I.

MATTOS, Luiz Alves de. O quadro-negro e sua utilização no ensino. $2^{\text {aa }}$ edição. Rio de Janeiro, Gráfica Editora Aurora, 1968.

Notas:

1 Doutor em Educação, vinculado aos Programas de Pós-Graduação em Educação da Universidade de Uberaba e da Universidade Federal de Uberlândia (jcaraujo.ufu@ gmail.com).

${ }^{2}$ A informática é um ramo do conhecimento dedicado ao tratamento da informação mediante o uso de computadores e demais dispositivos de processamento de dados.

3 Por sua vez, a telemática refere à ciência que trata da transmissão, à longa distância, de informação computadorizada; além disso, refere-se também ao conjunto dos serviços informáticos fornecidos através de uma rede de telecomunicações.

${ }^{4}$ Dispositivo de saída de dados utilizado em um conjunto com diascópios (retroprojetores) para projetar em telas imagens geradas na saída de vídeo do computador.

${ }^{5}$ Progresso, liberdade, razão, igualdade, democracia, representação política, ciência, educação do homem, escolarização universal, sociedade sem classes, desenvolvimento são alguns exemplos destas.

Recebido em: $\quad 25 / 11 / 11$

Aprovado em: $\quad$ 20/12/11 